\title{
Duodenal reflux during insulin-stimulated secretion
}

\author{
R. G. FABER, R. C. G. RUSSELL, C. M. S. ROYSTON, P. WHITFIELD, AND \\ M. HOBSLEY
}

From the Department of Surgical Studies, The Middlesex Hospital, London

SUMMARY Insulin-stimulated secretion has been studied in 67 subjects with intact vagi. The relationship between the changes in the concentrations of hydrogen and sodium ions in individual 10minute samples showed a highly significant negative correlation. In quantitative terms, this correlation could be explained by the mixing of isotonic gastric juice and'duodenal reflux but not by backdiffusion.

In 37 subjects duodenal juice was labelled with either bromsulphalein (BSP) or indocyanine green (ICG), both dyes being excreted only in the bile. In aspirated gastric juice there were highly significant positive correlations between the concentration of the dye and the concentration of duodenal reflux calculated from a formula based on the output of sodium ions.

The volume of duodenal reflux occurring during insulin-stimulated secretion was estimated from the sodium output in normal controls, in preoperative patients with duodenal ulcer, and in patients following vagotomy with or without a drainage procedure. Reflux following gastrojejunostomy greatly exceeded that occurring in all other groups. Reflux following vagotomy with no drainage procedure was less than that in preoperative patients, and in patients in whom pyloroplasty or gastrojejunostomy had been performed.

By analysing the outputs of electrolytes in maximally stimulated gastric juice, Hobsley (1974) has derived a formula based on the output of sodium ions for calculating the volume of duodenal reflux in a sample of gastric juice. A fundamental assumption in the derivation of this formula was that the concentration of sodium in the duodenal reflux was constant at about $146 \mathrm{mmol} / \mathrm{l}$. Fiddian-Green, Russell, and Hobsley (1972) and Fiddian-Green, Whitfield, Russell, Faber, and Hobsley (1974) examined, secretion when duodenal reflux was artificially exaggerated by an injection of secretin during maximal histamine infusion, and showed that, at least in these circumstances, this fundamental assumption is justified. Furthermore, the relationships between changes in the concentrations of sodium and hydrogen ions, and between the outputs of sodium and hydrogen ions, were as predicted by simple chemical theory (the mixing of isotonic acid and alkaline solutions) and were distinct from what would be expected if back diffusion were occurring. They also showed that when duodenal juice was labelled with indocyanine green (ICG), a dye excreted only in the bile, there was a highly significant correlation between the gastric

Received for publication 24 July 1974. juice concentrations of ICG and of calculated reflux based on the sodium formula.

The present study has examined gastric secretion during insulin tests; Faber, Russell, Parkin, Whitfield, and Hobsley (1974) have shown that secretion is approximately constant during the period one-half to two hours after an intravenous injection of insulin, and the object of this study was to determine whether the observed variations in outputs of water and sodium and hydrogen ions during this period were explicable in terms of duodenal reflux. To this end the quantitative relationships between outputs of sodium and hydrogen ions and between concentrations of sodium and hydrogen ions in 10minute samples during this period were investigated. A second aspect of the study was to label duodenal contents with one of two dyes, and to study the correlation between the dye concentration in the gastric aspirate and the proportion of reflux in the aspirate as calculated by the sodium formula. Finally, the formula was used to quantify reflux in various groups of subjects undergoing an insulin test.

\section{Experimental Design}

Each subject fasted and abstained from tobacco and 
all medication known to affect gastric secretion from midnight. Between 8.30 and 9 am the subject lay semi-recumbent on a couch, a specially prepared two-lumen nasogastric tube (Thomson, Russell, and Hobsley, 1973) was passed, and its correct position in the stomach checked by the water-recovery test of Hassan and Hobsley (1970). In most of the subjects phenol red was instilled into the stomach through the smaller lumen (Hobsley and Silen, 1969). An intravenous infusion was set up. In some of the subjects bromsulphalein (BSP, $15 \mathrm{~g} / 1$ in $9 \mathrm{~g} / 1$ sodium chloride solution) was injected intravenously at the rate of $10 \mathrm{ml}$ per hour starting 45 minutes before definitive collections of gastric juice were made. In certain other subjects indocyanine green (ICG) was injected intravenously at the rate of $645 \mathrm{mmol}$ $\mathrm{h}^{-1} \mathrm{~kg}^{-1}\left(0.5 \mathrm{mg} \mathrm{h}^{-1} \mathrm{~kg}^{-1}\right)$, starting one hour before the definitive collection of gastric juice. After a basal collection, soluble insulin $(0.2$ units $/ \mathrm{kg})$ was injected intravenously and gastric juice was collected at 10-minute intervals for a further two hours. Venous blood samples for the measurement of blood glucose were taken at intervals during each study, and only tests where adequate hypoglycaemia $(<40$ $\mathrm{mg} / 100 \mathrm{ml}$ ) was attained have been included in this study. The phenol red instillation, and the infusions of BSP or ICG when present, were continued throughout each study. The gastric juice for the period from half to two hours after the injection of insulin was designated the insulin-stimulated secretion.

\section{Clinical Material}

Studies were performed on 67 non-operated subjects (12 controls, 55 patients with duodenal ulcer) and on 152 patients (123 men, 29 women) following vagotomy with or without a drainage procedure for duodenal ulcer. In 11 subjects (10 men, one woman; eight before operation, three after vagotomy), BSP was used as a biliary marker and in these subjects phenol red was not instilled into the stomach because of spectrophotometric overlap (see Methods). In 26 subjects ( 22 men, four women; 11 before operation, 15 after vagotomy), ICG was used as a biliary marker, and in all these, and in all other studies, phenol red was instilled into the stomach. Informed consent was obtained from all subjects.

\section{Methods}

On each sample of gastric juice, after filtration through Whatman's no. 1 filter paper, the following measurements were made: volume $(\mathrm{ml})$, titratable acidity (Radiometer automatic titrator, titrations to pH 7), sodium, potassium, and chloride (EEL flame photometer and chloride meter), and phenol red, BSP, and ICG concentrations where applicable (Unicam SP spectrophotometer at 550, 580, and $800 \mathrm{~nm}$ respectively). The phenol red standard solution was handled as described by Hobsley and Silen (1969), and each ICG reading was corrected by the formula given by Fiddian-Green et al $(1972,1974)$.

\section{Calculations}

The volume $\left(\mathrm{V}_{\mathrm{obs}}\right)$ of each sample of gastric juice was divided by the recovery fraction of phenol red to allow for the pyloric losses and thereby determine the correct volume $\left(\mathrm{V}_{\text {cor }}\right)$. The volume of duodenal reflux, $V_{R}$, present in each sample was calculated from the sodium output and volume $\left(\mathrm{V}_{\text {cor }}\right.$ where phenol red was used, $V_{\text {obs }}$ where no phenol red was used) by the formula: $V_{R}=7.34 Q_{\mathrm{Na}}-0.0712 \mathrm{~V}$ - 1.281 (Fiddian-Green et al, 1972, 1974). The fractional concentration of reflux was then calculated by dividing $V_{R}$ by $V_{\text {cor }}$ or $V_{\text {obs }}$.

In each subject, the mean electrolyte concentrations and outputs were determined for the insulinstimulated period. The changes in sodium concentration, $\Delta\left[\mathrm{Na}^{+}\right]$and titratable acidity, $\Delta\left[\mathrm{H}^{+}\right]$, and in outputs of sodium, $\Delta \mathrm{Q}_{\mathrm{Na}}$, and acid, $\Delta \mathrm{Q}_{\mathrm{H}}$, were calculated by subtracting the mean value obtained for each subject from the value of the individual sample.

\section{Results}

ELECTROLYTE STUDY

In 470 samples during insulin-stimulated secretion in non-operated subjects, the changes in titratable acidity, $\Delta\left[\mathrm{H}^{+}\right]$, correlated significantly with the changes in sodium concentration, $\Delta\left[\mathrm{Na}^{+}\right],(\mathrm{r}=$ $-0.711, \mathrm{P}<0.001)$; the regression equation was: $\Delta\left[\mathrm{H}^{+}\right]=0.071-1.511 \Delta\left[\mathrm{Na}^{+}\right]$. The meaning of $1 \cdot 511$, the value obtained for the slope, will become clear in the discussion. In the same samples no significant correlation was obtained between the changes in the sodium and acid output, $\Delta \mathrm{Q}_{\mathrm{Na}}$ and $\Delta \mathrm{QH}_{\mathrm{H}}$.

\section{MARKERS OF DUODENAL JUICE}

Figure 1 shows the BSP concentration for each 10minute sample plotted against the concentration of calculated reflux, $V_{R} / V_{\text {obs. }}$. There is a highly significant correlation $(r=0.713, P<0.001)$. The intercepts on the $x$ and $y$ axes are not significantly different from zero. By non-parametric analysis, the correlation remains highly significant $\left(r_{s}=0.579, P\right.$ $<0.001$ ). A similar correlation was found between corrected ICG concentration and the concentration of calculated reflux in 197 10-minute samples $(r=$ $0.249, \mathrm{P}<0.001$ ). 


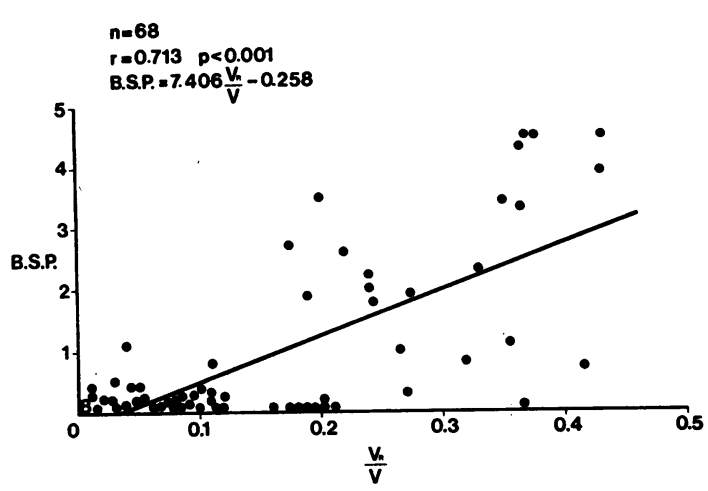

Fig 1 Bromsulphalein concentration in 68 10-minute samples of insulin-stimulated gastric secretion is plotted on the vertical axis, the fractional concentration of the calculated duodenal reflux in the gastric juice, $V_{R} / V$, on the horizontal axis. There is a highly significant correlation between the two measurements.

\section{REFLUX QUANTIFIED}

Figure 2 shows the volume of reflux, $V_{R} \mathrm{ml} /$ hour, calculated for normal controls, patients with duodenal ulcer, and patients following vagotomy with or without an accompanying drainage procedure. Data from subjects in whom phenol red was not used to quantify pyloric loss were not included in this part of the study. Means and standard errors of the means have been calculated after logarithmic transformation of the values to normalize the distributions. The table tabulates the statistical comparison between the groups, the probability values being obtained by Fisher's exact test. Reflux was significantly greater following gastrojejunostomy than in any of the other groups. Conversely reflux was significantly less following vagotomy with no drainage procedure than following vagotomy and either pyloroplasty or gastrojejunostomy, and also

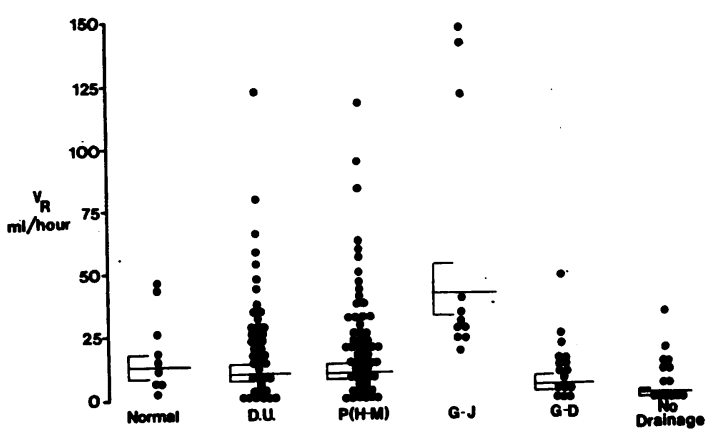

Fig 2 Average duodenal reflux during insulin-stimulated gastric secretion in normal subjects, and in duodenal ulcer patients before and after vagotomy and various drainage procedures. Means and standard errors of the means are indicated after logarithmic transformations.

Details of statistical comparisons are in the table. However, it is clear from this diagram that reflux was greatest after vagotomy and gastroenterostomy, least when vagotomy was performed without a drainage procedure.

was less than that occurring in the non-operated patients with duodenal ulcer. The numbers of normal controls were too small for strict comparison, but no differences were found between them and either nonoperated patients with duodenal ulcer, or duodenal ulcer patients following vagotomy unless that operation was accompanied by a gastrojejunostomy.

\section{Discussion}

\section{ELECTROLYTE STUDY}

Fiddian-Green et al $(1972,1974)$ have shown that following an injection of secretin during maximal histamine stimulation, duodenal juice refluxed in large volumes into the stomach and produced linked changes in the concentrations and outputs of sodium and

\begin{tabular}{|c|c|c|c|c|c|c|}
\hline $\boldsymbol{B}$ & Normal Controls & $\begin{array}{l}\text { Duodenal Ulcer } \\
\text { Before Operation }\end{array}$ & $\begin{array}{l}\text { Vagotomy plus } \\
\text { Pyloroplasty }\end{array}$ & $\begin{array}{l}\text { Vagotomy plus } \\
\text { Gastro- } \\
\text { jejunostomy }\end{array}$ & $\begin{array}{l}\text { Vagotomy plus } \\
\text { Gastro- } \\
\text { duodenostomy }\end{array}$ & $\begin{array}{l}\text { Vagotomy with } \\
\text { no Drainage }\end{array}$ \\
\hline $\begin{array}{l}\text { Normal controls } \\
\text { Duodenal ulcer before operatic } \\
\text { Vagotomy plus pyloroplasty } \\
\text { Vagotomy plus } \\
\text { gastrojejunostomy } \\
\text { Vagotomy plus gastro- } \\
\text { duodenostomy } \\
\text { Vagotomy with no drainage }\end{array}$ & $\begin{array}{l}\mathbf{P}=0.23 \\
P=0.22 \\
A>B \\
P=0.02 \\
P=0.15 \\
P=0.15\end{array}$ & $\begin{array}{l}P=0.16 \\
A>B \\
P=0.002 \\
P=0.08 \\
B>A \\
P=0.004\end{array}$ & 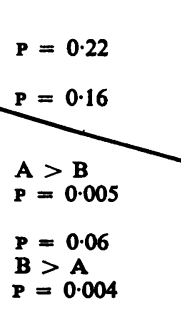 & $\begin{array}{l}\mathbf{B}>\mathbf{A} \\
\mathbf{P}=\mathbf{0 . 0 1 4} \\
\mathbf{B}>\mathbf{A} \\
\mathbf{P}=0.002 \\
\mathbf{B}>\mathbf{A} \\
\mathbf{P}=\mathbf{0 . 0 0 5} \\
\\
\mathbf{B}>\mathbf{A} \\
\mathbf{P}=0.0003 \\
\mathbf{B}>\mathbf{A} \\
P=0.0003\end{array}$ & $\begin{array}{l}P=0.15 \\
P=0.08 \\
P=0.06 \\
\mathbf{A}=\mathbf{B} \\
\mathbf{P}=0.0003 \\
P=0.17\end{array}$ & $\begin{array}{l}\mathbf{P}=0.15 \\
\mathbf{A}>\mathbf{B} \\
\mathbf{P}=\mathbf{0} .004 \\
\mathbf{A}>\mathbf{B} \\
\mathbf{P}=\mathbf{0 . 0 0 4} \\
\mathbf{A}>\mathbf{B} \\
\mathbf{P}=\mathbf{0 . 0 0 0 3} \\
\mathbf{P}=0.17\end{array}$ \\
\hline
\end{tabular}

Table Significance of differences of reflux volumes between the six groups

${ }^{1}$ Significance tested by Fisher's exact test. 
hydrogen ions. Thesechanges could only be explained in terms of mixing and chemical neutralization. No such artificial reflux was induced in this study, nor was a continuous maximal stimulant of gastric secretion used. However, Faber et al (1974) have shown that, following a single intravenous injection of insulin in non-operated subjects, secretion in the period from half an hour to two hours after the injection remained fairly constant, and the secretion during this period has therefore been considered to be approximately plateau secretion. For each individual sample, the changes in concentrations and outputs from the plateau averages were calculated for the sodium and hydrogen ions. A highly significant negative correlation was found between the concentrations, $\Delta\left[\mathrm{H}^{+}\right]$and $\Delta\left[\mathrm{Na}^{+}\right]$, the slope being -1.511 . This figure is not significantly different from -1.583 , the theoretical slope obtained by mixing isotonic gastric acid and isotonic alkaline reflux in varying proportions (Fiddian-Green $e t$ al, 1972, 1974). The relationship observed is incompatible with the back-diffusion theory of Teorell (1947), which would require a one-for-one relationship, and indicates that the variations in concentrations of water, sodium, and hydrogen ions during this approximate plateau period are due to variations in duodenal reflux.

No similar correlation was found between the changes in outputs of sodium and hydrogen ions, unlike the findings of Fiddian-Green et al $(1972,1974)$. This lack of correspondence in the findings of the two studies requires explanation. Fiddian-Green et al $(1972,1974)$ were studying reflux provoked artificially in large quantities during maximally stimulated gastric secretion. Under these circumstances, variations in corrected volume were due solely to changes in reflux with their corresponding (but opposite) changes in sodium and hydrogen ion concentrations and outputs. In the circumstances of the present study, gastric secretion was sufficiently near maximal to make the sodium and hydrogen ion concentrations in the gastric juice constant (Teorell, 1947) but nevertheless not quite on a plateau (Faber et al,1974). It follows that any increase in volume during the approximate plateau in the present studies might have been due to an increase in rate of the gastric secretions, resulting in a parallel increase in both sodium and hydrogen ion outputs. This factor could obscure the negative relationship between sodium and hydrogen ion outputs produced by the small changes in reflux occurring spontaneously in this study.

MARKERS OF DUODENAL REFLUX Both BSP and ICG were used because they are excreted only by the liver, and when given by intra- venous infusion, the concentrations of both dyes in hepatic bile (obtained by T-tube drainage after cholecystectomy) becomes constant (Wirts and Cantarow, 1942; Cherrick, Stein, Leevy, and Davidson, 1960). This appeared advantageous compared with the possibility of measuring one of the normal constituents of bile, because the output of these might well vary during the course of each study. Bromsulphalein was used initially, but because of spectrophotometric overlap phenol red could not be used concomitantly. Therefore, for later studies ICG was substituted.

The correlations between the concentrations of calculated reflux and both biliary markers are both highly significant. In the case of BSP the straightforward parametric correlation might be criticized on the grounds that neither variable appears to be normally distributed (see fig 1 ) and it is for this reason that we have also used a non-parametric analysis, Spearman's $r_{s}$. However, the correlation coefficient with BSP $(r=0.713)$ is considerably better than that with ICG $(r=0 \cdot 249)$. As described by Fiddian-Green et al $(1972,1974)$, there are considerable methodological problems in measuring ICG in gastric juice. There are also physiological problems with any such marker study: samples of reflux during a 10-minute period when no bile flowed into the duodenum would not be labelled, and the concentration of the label in duodenal contents would be sensitive to changing proportions of biliary and pancreatic contributions. Nonetheless, there was less than one chance in a thousand that either correlation arose by chance, and this finding supports the use of the formula derived from sodium output for measuring duodenal reflux.

\section{REFLUX QUANTIFIED}

The finding that duodenal reflux after gastrojejunostomy is greatly in excess of that occurring in normal controls, in preoperative patients with duodenal ulcer, and in patients following vagotomy and any other or no drainage procedure is interesting. It suggests that the well known fact that gastrojejunostomy alone will result in the healing of $50 \%$ of duodenal ulcers (Williams and Cox, 1969) may well not be due to diversion of the acid stream away from the duodenum, but rather to neutralization of the gastric acid by the refluxing alkaline jejunal contents. Indeed it is difficult to imagine the stomach selectively emptying through the stoma in the presence of such reflux when there is no obstruction to the via naturalis.

It is initially surprising that after vagotomy with no drainage procedure, reflux was not only less than after pyloroplasty or gastrojejunostomy, but also less than in the unoperated duodenal ulcer group. A possible explanation is that the decreased production 
of acid following vagotomy causes less pancreatic stimulation, and this factor of a lesser volume of duodenal juice plus the presence of an intact pylorus results in less reflux.

\section{Conclusions}

During the approximate plateau of insulin-stimulated secretion (1) changes in concentrations of sodium and hydrogen ions between individual samples of gastric juice can be explained by the mixture and chemical neutralization of the gastric acid with varying proportions of alkaline duodenal reflux, but not by back-diffusion; (2) the use of the sodium formula for estimating duodenal reflux is validated by the correlation between calculated reflux and reflux measured directly by dye-labelling of bile; (3) after vagotomy for duodenal ulcer $(a)$ if gastrojejunostomy has been performed, there is considerably more reflux than in preoperative patients or following any other drainage procedure, and $(b)$ if no drainage procedure has been added to the vagotomy less duodenal reflux occurs than before operation.

The gift of indocyanine green (Cardiogreen) by Messrs Hynson, Westcott, and Dunning of
Baltimore, Maryland, USA is gratefully acknowledged.

References

Cherrick, G. R., Stein, S. W., Leevy, C. M., and Davidson, C. S. (1960). Indocyanine green: observations on its physical properties, plasma decay and hepatic extraction. J. clin. Invest., $39,592-600$.

Faber, R. G., Russell, R. C. G., Parkin, J. V., Whitfield, P., and Hobsley, M. (1974). The predictive accuracy of the postvagotomy insulin test after vagotomy: a new interpretation. Gut, 15, 347-348.

Fiddian-Green, R. G., Russell, R. C. G., and Hobsley, M. (1972). Secretion-induced pyloric 'reflux: verification of the mathematical formula for eliminating reflux in gastric aspirate. Brit. J. Surg., 59, 903.

Fiddian-Green, R. G., Whitfield, P., Russell, R. C. G., Faber, R. G., and Hobsley, M. (1974). Indocyanine green as a marker of duodenal reflux in aspirated gastric juice. Brit. J. Surg., 61, 323-324.

Hassan, M. A., and Hobsley, M. (1970). Positioning of subject and of nasogastric tube during a gastric secretion study. Brit. med. J., 1, 458-460.

Hobsley, M. (1974). Pyloric reflux: a modification of the two-component hypothesis of gastric secretion. Clin. Sci. molec. Med., 47, 131-141.

Hobsley, M., and Silen, W. (1969). Use of an inert marker (phenol red) to improve accuracy in gastric secretion studies. Gut, 10, 787795.

Teorell, T. (1947). Electrolyte diffusion in relation to the acidity regulation of the gastric juice. Gastroenterology, 9, 425.443.

Thomson, J. P. S., Russell, R. C. G., and Hobsley, M. (1973). Doublelumen tube for gastric secretion studies. Brit. med. J., 3, 175 .

Williams, J. A., and Cox, A. G. (1969). In After Vagotomy, edited by J. A. Williams and A. G. Cox, p. 418. Butterworth, London.

Wirts, C. W., Jr., and Cantarow, A. (1942). A study of the excretion of br omsulphthalein in the bile. Amer. J. dig. Dis., 9, 101-106. 